\title{
A EDUCAÇÃO AMBIENTAL NAS ESCOLAS ESTADUAIS DE ENSINO MÉDIO EM CAMPO GRANDE, MS
}

\author{
Nilce Romero Lucchese ${ }^{1}$ \\ Gilberto Luiz Alves ${ }^{2}$ \\ Universidade Anhanguera - Uniderp
}

\section{RESUMO}

Este artigo tem como objeto a educação ambiental nas escolas estaduais de ensino médio da cidade de Campo Grande, MS. A relevância do tema está relacionada à desenfreada exploração de bens naturais que resulta em exaustão dos recursos existentes e crise ambiental. Essa tendência tem sido imanente ao desenvolvimento da sociedade capitalista. Como um dos recursos para enfrentar tal crise, vem ganhando importância a educação ambiental. No Brasil ela é preconizada como tema transversal nos currículos de educação básica, daí ser procedente a investigação da forma como vem sendo tratada nas escolas. Com base em Alves, Comenius, Hobsbawm, Bursztyn e Persegona, Mészáros e Ribeiro, a análise evidencia como foi produzida historicamente a questão ambiental e como se deu a emergência da educação ambiental como recurso para enfrentá-la, além de descrever como os professores de Biologia e Geografia, áreas mais próximas da EA, utilizam os instrumentos de trabalho didático. A conclusão é a de que, por privilegiarem os manuais didáticos especializados, esses professores acabam comprometendo a visão de transversalidade proposta pelos currículos.

Palavras-chave: meio ambiente, currículo, tema transversal.

\section{ENVIRONMENTAL EDUCATION IN STATE HIGH SCHOOLS IN CAMPO GRANDE, MS}

\begin{abstract}
The aim of this article is environmental education in state high schools in Campo Grande, Mato Grosso do Sul. The relevance of this subject is related to the unrestrained exploitation of natural resources resulting in environmental crisis. This tendency has been inherent for the development of the capitalist society. As a resource to face this crisis, environmental education is gaining in importance. In Brazil, it is recommended as a crosscutting theme in the curricula of basic education, hence it is founded on how the investigation is being addressed in schools. Based on Alves, Comenius, Hobsbawm, Bursztyn and Persegona, Mészáros and Ribeiro, the analysis make evident how the environmental question has been historically produced and how the emergence of environmental education is a resource to face it, also describing how the teachers of Biology and Geography, fields more closely related to EE, use the tools for didactic work. The conclusion is that, for they have privileged specialized didactic manuals, these teachers compromise the transversality view proposed by the curricula.
\end{abstract}

Keywords: environmental issues, curriculum, transverse theme.

\section{Introdução}

A discussão centrada nos temas relacionados ao meio ambiente, especialmente a partir das últimas décadas do século XX, decorre do fato de o planeta Terra estar vivendo intensa crise ambiental. Embora haja divergências em alguns aspectos, há o consenso de 
que se o quadro não for modificado, põe em risco a sobrevivência da humanidade e demais seres vivos.

O surgimento da educação ambiental foi uma das respostas aos desequilíbrios causados ao meio ambiente. Dessa forma há a necessidade de entendê-la no conjunto das condições históricas que a determinaram e de apreendê-la na sua gênese e desenvolvimento para saber como e por que foi produzida.

Enquanto resposta à questão ambiental, a educação ambiental (EA) é entendida como o conjunto dos "processos por meio dos quais o homem e a coletividade constroem valores sociais, conhecimentos, habilidades, atitudes e competências voltadas para a conservação do meio ambiente, bem de uso comum do povo, essencial à sadia qualidade de vida e sua sustentabilidade." (BRASIL, Lei n ${ }^{\circ} 9.795$, art. 1º 1999)

Tendo como referência esse entendimento, a lei consagrou a educação ambiental também no âmbito da escola. Segundo o que está posto nas diretrizes curriculares nacionais e definido, igualmente, nos Parâmetros Curriculares Nacionais (PCN), o meio ambiente é tema curricular transversal e a educação ambiental é o âmbito próprio ao seu tratamento. Ressalte-se que, sendo o meio ambiente tema transversal, deve permear todas as disciplinas do currículo.

Assim, o presente estudo tem como objeto o tratamento didático conferido à educação ambiental nas escolas estaduais de Campo Grande, Estado de Mato Grosso do Sul. Os fundamentos teóricos são buscados em Alves (2004; 2005; 2008), Comenius (2001), Hobsbawm (2004), Bursztyn e Persegona (2008), Mészáros (2003; 2011), Ribeiro (1998), entre outros.

Por entender que a "centralidade da relação educativa é exercida pelo instrumento de trabalho didático" (ALVES, 2005, p.19), a investigação procurou detectar os tipos de recursos instrumentais usados pelos professores ao abordarem a educação ambiental e, ainda, como os docentes deles se servem nas aulas. Para a consecução do presente estudo, foi realizado o levantamento dos instrumentos de trabalho didático usados em Geografia e Biologia, disciplinas mais próximas à discussão do meio ambiente e, portanto, centrais na abordagem transversal da educação ambiental.

\section{A Questão Ambiental e a Educação Ambiental na Sociedade Capitalista}

Registro de Engels, datado de 1878, apresenta um quadro infausto sobre as condições de vida e de trabalho do proletariado urbano. A situação dos países mais avançados na época, como a Inglaterra, prenunciava cenário de um mundo urbano miserável e degradante, produzido pela industrialização e seus efeitos ambientais.

Houve um domínio das forças da natureza para colocá-las ao serviço do homem, e a multiplicação dessa situação resulta em um futuro devastado do ponto de vista natural e social. E ainda, como consequência causaria excesso de trabalho e uma miséria crescente nas massas e uma explosão de crises a cada década. (ENGELS, 1978, p. 27-8)

Para Guimarães, na sociedade burguesa o capital se colocou como centro da natureza e passou a utilizá-la em seu favor desmedidamente.

A humanidade vem criando uma postura antropocêntrica, que nos causa um grande sentimento de distanciamento em relação à natureza. Para esse modelo societal o meio ambiente e o ser humano são concebidos de modo dicotômico. Historicamente o ser humano inserido nesse modelo societário sente-se separado, não-integrado ao ambiente natural. Percebese esse ambiente como suporte para seu desenvolvimento a partir de uma 
visão servil, utilitarista e consumista, de dominação totalitária da natureza, potencializando uma desnaturalização da humanidade. Rompem, assim, as relações de equilíbrio entre seres humanos em sociedade e o meio ambiente. Este distanciamento entre seres humanos e natureza produz a degradação de ambos. (GUIMARÃES, 2007, p. 25)

Distanciado da natureza, o homem não mais se sentiria dela integrante, passando a encará-la como reserva infindável de recursos disponíveis, passíveis de serem transformados em bens consumíveis. Ao mesmo tempo, a produção da riqueza teria se colocado a serviço da reprodução do próprio capital e não ao atendimento das necessidades básicas da humanidade.

No princípio da civilização, o impacto da vida humana sobre o ambiente era limitado, o que assegurava o equilíbrio dessa relação. Os deslocamentos espaciais variavam de acordo com as necessidades da vida biológica. As relações sociais só mudaram sensivelmente a partir do maior domínio humano do ambiente, situação que levou os pequenos bandos móveis à sedentarização.

Para satisfazer necessidades ligadas à alimentação, surgiram as primeiras formas de agricultura. "Estas se iniciam, provavelmente, pela horticultura de frutos e tubérculos nas áreas tropicais e, nas regiões temperadas e frias, pelo cultivo de cereais, uns e outros anteriormente coletados nos mesmos sítios". (RIBEIRO, 1998, p. 83)

Com a domesticação dos animais, além da força humana, criou-se nova fonte de energia muscular que se aplicou à montaria e à tração de arados e carros, ampliando a capacidade produtiva do homem e sua mobilidade espacial.

Desde a sociedade escravista, diferentes povos organizaram sua vida econômica sob a forma de produção especializada de bens. De acordo com Ribeiro, "os bens eram produzidos predominantemente como valores de uso para o consumo dos próprios produtores e de outros membros de seu círculo doméstico".

A produtividade do trabalho humano se elevou muito lentamente, ao longo de milhares de anos, como decorrência do aperfeiçoamento dos instrumentos de trabalho e das técnicas para o cultivo da terra, aliados ao manejo dos animais. O controle progressivo do homem sobre a produção de alimentos resultou na obtenção de excedentes e incremento do comércio.

Nessa etapa não há lugar ainda para a acumulação privada de bens, nem para a apropriação dos produtos do trabalho alheio. Os excedentes alimentares ou de outro tipo - geralmente produto da dadivosidade da natureza em certas quadras do ano - são destinados a gastos supérfluos, com atos de fé, ou ao consumo festivo. Mesmo quando esses bens são apropriados pelos chefes dos grupos familiares, revertem geralmente à coletividade, após sua morte, ou são transferidos segundo regras de parentesco classificatório que incluem grande parte, senão a totalidade, do grupo local. (RIBEIRO, 1998, p. 88)

Até a época do feudalismo, apesar do incremento da produtividade do trabalho humano e das mudanças nas relações sociais, o impacto da existência do homem sobre o ambiente mantinha certo nível de equilíbrio.

A especialização da força de trabalho e dos instrumentos de trabalho, a instauração das manufaturas, as navegações e as grandes descobertas, bem como a integração do mercado mundial, dinamizaram a economia e marcaram a ascensão do capital mercantil.

A Revolução Francesa, no plano político, e o advento da Revolução Industrial, no plano econômico, representaram a consolidação do estado burguês e do modo de produção 
capitalista. Em paralelo, a elevação sem precedentes das forças produtivas se fazia acompanhar de agressiva exploração da força de trabalho e intensa degradação ambiental.

A modernidade representada pela Revolução Industrial iniciada no século XVIII é o marco de uma brusca mudança no modo de relação entre o homem e a natureza, bem como nas esferas produtiva e populacional. Processos que antes se davam lentamente, como a degradação de ambientes naturais e o consumo de meios não renováveis, passam a ocorrer de forma acelerada. (BURSZTYN; PERSEGONA, 2008, p. 14)

Com a expansão das cidades e decorrente concentração da população nesses espaços, ocorreu uma crescente deterioração da qualidade de vida dos habitantes pelas precárias condições de higiene, de saneamento básico e de trabalho, que ocasionaram, inclusive, epidemias graves.

É expressiva a descrição feita por Engels das cidades industriais de Manchester, Birmingham, Leicester, Liverpool, Preston, entre outras, a partir de suas observações diretas nos anos de 1842 a 1844. Seus relatos sobre as habitações, os hábitos de alimentação e de vestuário da classe trabalhadora, bem como sobre as condições de trabalho, revelam uma situação de extrema exploração realizada pelo capital.

Nessas condições, os trabalhadores perderam os laços tradicionais com a terra de seus ancestrais, durante as convulsões sociais instauradas pelo capitalismo, e passaram a auferir salários insuficientes para manter suas famílias em condições dignas de existência. (HOBSBAWM, p. 186, 2004)

O descontrole na utilização dos recursos ambientais e seu avanço acelerado, dentro do sistema capitalista, determinaram a necessidade inadiável de discussão da relação entre o homem e o meio ambiente, pois emergiu a consciência de que os recursos naturais caminham para o esgotamento de forma a comprometer a própria existência da humanidade e de outros seres vivos.

A destruição do meio ambiente, a serviço dos interesses cegos do capital, assumiu proporções tais - dramaticamente ilustradas pela terrível calamidade que atingiu, nos últimos dias do século $\mathrm{XX}$, o povo da Venezuela, causada pelo desflorestamento irresponsável e por projetos "especulativos" - que mesmo que amanhã se reverta o processo, seriam necessárias várias décadas para produzir mudanças significativas, visando neutralizar a articulação perniciosa, auto-impelida e auto-sustentada do capital, que deve perseguir sua "racionalidade" expressa em termos imediatamente "econômicos", por meio da linha de menor resistência; ademais implicações potencialmente letais de se brincar com a natureza pelo uso imprudente da "biotecnologia", "clonagem" e pela modificação genética descontrolada de alimentos, sob o ditame de gigantes empresariais gananciosos e de seus governos. (MÉSZÁROS, 2003, p. 87)

Para este filósofo, "o sistema que nós temos hoje, está de fato destruindo a humanidade, a natureza e os recursos naturais. Porque se baseia no crescimento a todo custo e a todo preço". (MÉSZÁROS, 2011, n.p.)

O Brasil entrou para a história como parte do processo de integração do mercado mundial, como resultado, em grande parte, da cultura da cana de açúcar e do engenho.

O Brasil, como todo o Novo mundo, surge no mapa da história moderna justamente no momento em que a hegemonia europeia, sob a égide da expansão comercial, abria novas fronteiras. De forma avassaladora, a chegada dos ibéricos nas Américas é um retrato inicial do que viria em seguida. Não foi apenas uma conquista militar de civilizações menos 
armadas e ambiciosas. Foi também uma conquista do seu meio natural, impondo-se uma nova escala mercantil de apropriação. (BURSZTYN; PERSEGONA, 2008, p.14)

No Brasil, também ocorreram processos semelhantes aos que se deram nas nações industrializadas, como o crescimento populacional e a urbanização. Como no resto do mundo, por força da industrialização intensiva, no País o século XX foi marcado pelos fatos e eventos que fizeram emergir a questão ambiental.

Entre os Censos de 1940 e 2000, a população brasileira cresceu quatro vezes. O Brasil rural tornou-se progressivamente urbano: a taxa de urbanização evoluiu de $31,3 \%$ para $81,2 \%$. No período em foco, a agricultura, a pecuária e a silvicultura, que, em 1940 representavam $32,6 \%$ da população ocupada, caiu para $17,9 \%$, em 2000. (INSTITUTO BRASILEIRO DE GEOGRAFIA E ESTATÍSTICA, 2007, n.p.)

Junto ao crescimento demográfico e à urbanização, ocorreu a introdução de novas tecnologias agrícolas, como aquelas aplicadas na produção de agrotóxicos, adubos inorgânicos e engenharia genética, que "possibilitou inúmeros avanços na agricultura e na pecuária, permitindo cada vez maior produção de cereais, frutas, carne e leite por área de terra”. (BRANCO, 1997, p. 18)

Mas a modernização agrícola começou a sofrer críticas que se intensificaram progressivamente. "Muitos questionam a sustentabilidade de um projeto baseado em monoculturas e que faz uso em grande escala de fertilizantes, agrotóxicos e insumos de alto custo", afirma Faleiros (2007, n.p.). O mesmo autor, também considera os maus tratos ocasionados ao meio ambiente e o avanço das fronteiras agrícolas, como pontos negativos.

De maneira geral, uma série de acidentes ambientais e a progressiva degradação da qualidade de vida urbana aumentaram a urgência da discussão ambiental.

Em março de 1967, por exemplo, o navio Torrey Canyon derramou petróleo ao longo da costa norte da França. Cientistas suecos afirmaram que a morte de peixes e outros organismos em milhares de lagos da Suécia era resultado do longo alcance de poluição aquática vinda da Europa Ocidental. (INSTITUTO BRASILEIRO DO MEIO AMBIENTE E DOS RECURSOS NATURAIS RENOVÁVEIS, 2004, p. 2)

Em 5 de junho de 1972, em Estocolmo, Suécia, foi realizada a Conferência das Nações Unidas sobre o Meio Ambiente Humano, considerada marco histórico. A Conferência, ao discutir a relação entre o meio ambiente e o desenvolvimento econômico, assistiu, entre outras manifestações, ao confronto entre as perspectivas dos países desenvolvidos e dos países em desenvolvimento. Se, por um lado, os países desenvolvidos preocupados com o efeito da devastação ambiental sobre a Terra propunham um programa internacional para conservação dos recursos naturais e genéticos do planeta, por outro, os países em desenvolvimento, assolados pela pobreza, com graves problemas de moradia e saneamento básico, afirmavam a necessidade de desenvolvimento econômico.

Como resultado das discussões, a Conferência de Estocolmo instituiu o Programa Internacional de Educação Ambiental (PIEA), sob os auspícios da Organização das Nações Unidas para a Educação, a Ciência e a Cultura (UNESCO) e do Programa das Nações Unidas para o Meio Ambiente (PNUMA), para, junto aos Estados e organismos da ONU, concretizar seus objetivos. O PIEA foi consolidado dois anos mais tarde, por meio da Conferência Intergovernamental sobre Educação Ambiental, conhecida como Conferência de Tbilisi. 
No ano de 1975 foi realizada a Conferência de Belgrado, Iugoslávia, promovida pela UNESCO. O documento internacional firmado pelos países participantes avaliou prioridades, avanços e carências na área de Educação Ambiental e passou a ser referência para a área. O documento oficial resultante tratou do crescimento econômico e do desenvolvimento tecnológico sem precedentes, os quais, ao mesmo tempo em que trouxeram benefícios para a humanidade, produziram sérias consequências ambientais e sociais, como a maior desigualdade econômica entre os homens e deterioração do meio ambiente em escala mundial.

A Carta de Belgrado, considerada documento norteador para o desenvolvimento da educação ambiental, tornou-se, também, influente contribuição para o entendimento do crescimento desordenado e proposta de correção de rumos para a educação. Segundo o que preconiza, as crianças e os jovens deveriam receber educação ambiental com caráter contínuo, interdisciplinar, com perfil pluridimensional, visando à mudança de valores, atitudes e comportamentos sociais, de forma a assegurar a participação de todos para a solução de problemas ambientais.

A partir de então, foram intensificados esforços para a adoção de medidas que favoreçam o crescimento econômico com redução dos efeitos danosos ao meio ambiente, com a reutilização de materiais e, acima de tudo, que assegurem a paz por meio da coexistência e cooperação entre as nações. A década de 1980 definiu este cenário ideal como sinônimo de "desenvolvimento sustentável".

O Brasil, à época da ditadura militar, defendera uma política de desenvolvimento econômico alheia às demandas do meio ambiente.

O governo brasileiro, na Conferência de 1972, liderou o bloco de países em desenvolvimento que tinham posição de resistência ao reconhecimento da importância da problemática ambiental (sob o argumento de que a principal poluição era a miséria) e que se negavam a reconhecer o problema da explosão demográfica. A posição do Brasil - na época sob o governo militar - era a de "Desenvolver primeiro e pagar os custos da poluição mais tarde", como declarou o Ministro Costa Cavalcanti, na ocasião. (VIOLA; LEIS, 1992, p. 83)

Com a redemocratização, a Constituição de 1988, pautada na definição de meio ambiente como um complexo de relações entre o mundo natural e os seres vivos, reconheceu as necessidades sociais ligadas a ele em seu Artigo 225:

Todos têm direito ao meio ambiente ecologicamente equilibrado, bem de uso comum do povo e essencial à sadia qualidade de vida, impondo-se ao Poder Público e à coletividade o dever de defendê-lo e preservá-lo para as presentes e futuras gerações. (BRASIL, 2008, n.p.)

O reconhecimento das necessidades sociais ligadas ao meio ambiente equilibrado, posto na Constituição Brasileira de 1988, contribuiu para chamar atenção dos brasileiros e motivar seu interesse por ele.

As Constituições que precederam a de 1988 jamais se preocuparam com a proteção do meio ambiente de forma específica e global. Nelas sequer uma vez foi empregada a expressão "meio ambiente", a revelar total despreocupação com o próprio espaço em que vivemos. (MILARÉ, 1991, p. 3)

Nesse sentido, cabe mencionar a definição ligada ao Desenvolvimento Humano Sustentável, de acordo com o Programa das Nações Unidas para o Desenvolvimento (PNUD), que situa os homens no centro do desenvolvimento. "Este conceito defende e 
promove a adoção de políticas públicas que consideram as pessoas, e não a acumulação de riqueza, o propósito final do desenvolvimento". (PROGRAMA DAS NAÇÕES UNIDAS PARA O DESENVOLVIMENTO, 1992, p.5)

Junto a essa definição, surge o Índice de Desenvolvimento Humano (IDH) ${ }^{3}$, que visa aferir o grau de Desenvolvimento Humano Sustentável de uma sociedade, não apenas pelo rendimento nacional, como era prática havia tempos, mas também pela esperança de vida e pela alfabetização.

Criado pelo professor Amartya Sen, ganhador do Prêmio Nobel de economia em 1998, o IDH, ao contrário do PIB per capita, focaliza o indivíduo e sua comunidade, revelando com que eficácia o crescimento econômico é transformado em bem estar para toda a população. (PROGRAMA DAS NAÇÕES UNIDAS PARA O DESENVOLVIMENTO, 1992, p. 5)

Formulados ideologicamente no campo do liberalismo, os princípios do Desenvolvimento Humano, conforme relatório das atividades do Programa de Desenvolvimento das Nações Unidas (PNUD) no Brasil

[...] estão pautados no desenvolvimento das pessoas, por meio da ampliação das capacidades, potencialidades e direitos de escolhas individuais, na participação ativa dos indivíduos e comunidades; na definição do processo de desenvolvimento, do qual são, ao mesmo tempo, sujeitos e beneficiários e, ainda, na forma apropriada e equitativa de a riqueza produzida pela nação retornar para cada um de seus membros. (PROGRAMA DAS NAÇÕES UNIDAS PARA O DESENVOLVIMENTO, 1992, n.p.)

Acentue-se que as bases para a educação ambiental já estavam formuladas no documento final da Conferência Intergovernamental de Educação Ambiental de Tbilisi, República da Geórgia, ex-União Soviética. Essa Conferência, realizada entre 14 e 26 de outubro de 1977, foi promovida pela UNESCO e pelo Programa das Nações Unidas para o Meio Ambiente (PNUMA) da Organização das Nações Unidas (ONU).

O documento compõe-se de quarenta e uma recomendações. Seus princípios, objetivos, estratégias e definições para a Educação Ambiental até hoje são adotados em todo o mundo.

Formalmente, o processo de institucionalização da educação ambiental no Brasil teve início em 1973, com a criação da Secretaria Especial do Meio Ambiente (SEMA), vinculada ao Ministério do Interior. Parte de suas atribuições tem estado voltada para o "esclarecimento e a educação do povo brasileiro para o uso adequado dos recursos naturais, tendo em vista a conservação do meio ambiente". Essa secretaria assumiu o compromisso de ministrar a capacitação de recursos humanos e iniciar a sensibilização da sociedade para as questões ambientais.

Do ponto de vista legal, a promulgação da Constituição Federal, em 1988, por meio do Capítulo VI, artigo 225, reforçou a necessidade de um trabalho efetivo direcionado para soluções ambientais e, ainda, afirmou a intenção de "promover a educação ambiental em todos os níveis de ensino e a conscientização pública para a preservação do meio ambiente". (BRASIL, 2008, n.p.)

Após onze anos da aprovação da Constituição Federal de 1988, foi instituída a Política Nacional de Educação Ambiental que integrou as escolas públicas e privadas ao exercício da educação ambiental. 
Art. 7o. A Política Nacional de Educação Ambiental envolve em sua esfera de ação, além dos órgãos e entidades integrantes do Sistema Nacional de Meio Ambiente - Sisnama, instituições educacionais públicas e privadas dos sistemas de ensino, os órgãos públicos da União, dos Estados, do Distrito Federal e dos Municípios, e organizações nãogovernamentais com atuação em educação ambiental. (BRASIL, 1999, n.p.)

Quanto a Mato Grosso do Sul, é importante lembrar que o crescimento econômico da região Centro-Oeste, desde a época da Ditadura Militar, fora impulsionado pela construção de estradas, abertura de terras para lavoura e pecuária, edificação de cidades e, sobretudo, pela pesca e caças predatórias. Contudo, sensível à preservação do meio ambiente, o primeiro governador da nova unidade da federação, Harry Amorim Costa, nomeado após a divisão de Mato Grosso, em 1979, criou o Instituto de Preservação e Controle Ambiental de Mato Grosso do Sul (INAMB) pelo Decreto n. 9, de $1^{\circ}$ de janeiro de 1979 (LEMOS, 2004, p.14). As distorções do desenvolvimento agrícola do Estado motivaram a realização de eventos científicos e nutriram o movimento ambientalista, promovendo, no ano seguinte, 1980, o marco inicial da educação ambiental em Mato Grosso do Sul, corroborada por campanhas educativas a favor da inserção da disciplina Preservação da Natureza no currículo das escolas da Rede Estadual de Ensino.

Portanto, com base nesses dados, pode-se reconhecer que houve, desde a criação do Estado, alguma preocupação de sua política educacional com a relação entre o homem e o meio ambiente.

Cumpre mostrar como a educação ambiental tem sido tratada atualmente na escola. Para tanto, são enfatizados os instrumentos didáticos utilizados pelos professores nas escolas estaduais de ensino médio, em Campo Grande.

\section{Formas de Tratamento da Educação Ambiental nos Currículos Escolares}

Do ponto de vista teórico, a exposição da gênese dos instrumentos didáticos na escola moderna é fundamental para a compreensão da centralidade alcançada pelos manuais didáticos. Na sequência são discutidas a origem e as funções do manual didático no processo de produção material da escola moderna, segundo Alves (2004, 2005, 2008).

A obra Didática Magna, escrita por Comenius, no século XVII, propõe uma organização do trabalho didático fundado na divisão manufatureira do trabalho. $\mathrm{O}$ trabalho didático, à época, deveria obedecer às mesmas características do trabalho manufatureiro,

[...] onde a divisão do trabalho permitiria que diferentes operações, realizadas por trabalhadores distintos, se desenvolvessem de forma rigorosamente controlada, segundo um plano prévio e intencional que as articulava, para produzir mais resultados com a economia de tempo, de fadiga e de recursos. (ALVES, 2004, p. 83)

$\mathrm{Na}$ referida perspectiva, o manual didático chega aos educadores especializados em áreas distintas do saber, com vistas a assegurar a transmissão de conhecimento e, também, com a finalidade de instruí-los na metodologia que deveriam utilizar.

À época não havia tantos homens com formação mínima necessária para atender à demanda de "educação para todos". Comenius, consciente desse fato, concebeu o manual didático, instrumento de trabalho que ganhou centralidade na relação educativa. No manual didático, ele depositou a função de assegurar a transmissão do conhecimento para compensar as dificuldades advindas do desconhecimento do professor. 
O manual didático, além de resumir um programa de conteúdos informativos, disposto em uma ordem dada por sequência e relacionamento, condicionaria, ainda, os procedimentos docentes necessários ao desenvolvimento desse programa, fixados previamente. (ALVES, 2005, p. 70)

O ponto que se deseja enfatizar é que o manual, instrumento produzido pela escola do século XVII para "ensinar tudo a todos", arrastou-se no tempo, se cristalizou e chegou aos nossos dias. De acordo com Alves (2005, p. 232), esse "anacronismo é, hoje, um dos mais sérios empecilhos que a escola enfrenta para ascender ao conhecimento humano culturalmente significativo".

Para Alves (2008), o manual presente na escola contemporânea gera uma séria limitação, pois determina uma relação vazia e nada criativa entre professor e aluno, na medida em que o professor está atrelado ao manual didático como fonte e o aluno, igualmente, só se limita à sua leitura para a realização da prova.

Essa relação é problemática porque não desperta nenhum tipo de criatividade e nem incute no aluno a necessidade de pensar. Aliás, ela impede que professor e aluno pensem de modo a assimilarem o conhecimento culturalmente significativo. Por meio dos manuais, a instituição escolar, por sua vez, passa a atuar como mera reprodutora das informações incorporadas ao manual, sem que se instaure qualquer discussão que as transcendam. Para Alves "Ao realizar-se por meio do manual didático, a transmissão do conhecimento na escola, (...), se identificou, de fato, com a difusão do conhecimento vulgar". (ALVES, 2008, p. 106)

Assim, ao discutir as formas de tratamento dadas à educação ambiental nas escolas, deve-se considerar a organização do trabalho didático e seus instrumentos, mantidos até nossos dias. Somente por meio desse aporte é possível pensar e discutir o processo de construção do conhecimento culturalmente significativo.

Cabe ressaltar a importância do conhecimento das leis, políticas e diretrizes curriculares. A Resolução $n^{\circ}$ 2, de 30 de janeiro de 2012, expedida pelo Ministério de Educação, Conselho Nacional de Educação e Câmara da Educação Básica, dispõe:

Art.10. Em decorrência de legislação específica, são obrigatórios: (...) II Com tratamento transversal e integradamente, permeando todo o currículo, no âmbito dos demais componentes curriculares: (...) Educação ambiental (Lei n $^{\circ} 9.795 / 99$, que dispõe sobre a Política Nacional de Educação Ambiental).

Art.13. As unidades escolares devem orientar a definição de toda a proposição curricular, fundamentada na seleção dos conhecimentos, componentes metodológicos, tempos, espaços, arranjos alternativos e formas de avaliação, tendo presente: (...)

$\mathrm{V}$ - a sustentabilidade socioambiental como meta universal, desenvolvida como prática educativa integrada, contínua e permanente, e baseada na compreensão do necessário equilíbrio e respeito nas relações do ser humano com seu ambiente. (BRASIL, Resolução $N^{\circ}$ 2, 2012, p. 3-5)

Em consonância com as diretrizes da resolução $n^{0}$ 2, os Parâmetros Curriculares Nacionais - PCN (1997) consideram a Educação Ambiental tema transversal e, definem como os demais, sua escolha teria sido determinada pela urgência social, pela abrangência nacional, pela possibilidade de ensino e aprendizagem no ensino fundamental pelo favorecimento da compreensão da realidade e da participação social. O que se propõe é que os temas transversais ganhem destaque no currículo, de modo a envolver em sua realização os conteúdos das várias áreas e disciplinas. 
O Ministério de Educação (MEC) buscou espelhar-se na experiência da Espanha ao adotar os temas transversais no currículo, experiência que vem se desenvolvendo desde 1989 naquele país. É o que demonstra o conteúdo de um texto de Moreno, da Universidade de Barcelona.

\begin{abstract}
Os temas transversais destinam-se a superar alguns efeitos perversos, aqueles dos quais a sociedade atual se conscientizou, que, junto com outros de grande validade, herdamos da cultura tradicional. Estas questões devem ocupar um lugar secundário no ensino só porque não faziam parte das preocupações da ciência clássica? Se fizéssemos isto, estaríamos concedendo mais importância às preocupações do passado que às do presente, isto é, estaríamos vivendo e educando com o olhar continuamente voltado para trás. (MORENO, apud BUSQUETS et alii, 1997, p. 36)
\end{abstract}

No discurso da autora, de inequívoca inspiração liberal, os temas transversais têm por base o entendimento de que a escola é lugar de formação do cidadão. Isso implica o reconhecimento de que se vive em uma sociedade complexa, marcada pela multiplicidade, pela estratificação e pela diversidade, que exige o respeito à vida e aos direitos humanos básicos enquanto fundamentos de convicções democráticas. É nesse quadro que emerge a necessidade da educação ambiental, associada às práticas de cidadania de um tempo que impõe a recuperação da relação equilibrada entre o homem e o meio ambiente. Daí, igualmente, a necessidade de tratamento transversal e integrado do meio ambiente no currículo, de forma a permear todos os seus componentes.

Levando em conta as proposições descritas, são discutidas, a seguir, as práticas de educação ambiental detectadas em quatro escolas estaduais de Campo Grande, MS. Por ser a educação ambiental tema transversal nos currículos, optou-se por entrevistar professores de áreas do conhecimento mais próximas da questão ambiental: Geografia e Biologia.

\title{
Crítica aos Manuais Didáticos Utilizados nas Escolas
}

O uso dos manuais didáticos reforça a tese, de que eles são centrais para a veiculação do conhecimento no âmbito escolar. É o que se revela nas entrevistas com os professores e na análise dos manuais didáticos.

As questões norteadoras das entrevistas permitiram identificar os instrumentos didáticos usados em EA por quatro escolas estaduais de ensino médio em Campo Grande MS.

A EA é desenvolvida, segundo os professores, quando são abordados temas relacionados aos impactos ambientais e aos encontros internacionais e nacionais que tratam do assunto. As temáticas como o lixo, a degradação do solo, a reciclagem, que dão margem à leitura de artigos relacionados à questão ambiental, bem como os conteúdos de ecologia trazidos pelos manuais didáticos. Há quem afirme, explicitamente, que "desenvolve o tema por meio de subtemas trazidos pelo conteúdo do livro didático". (Professor Be, Entrevista realizada em 10.06.2011) ${ }^{1}$

Quando solicitados, os professores indicaram como recursos mais utilizados desde slides, consultas à legislação ambiental, leituras das revistas National Geographic e Superinteressante, utilização de livros em geral e, ainda, de DVD. São eles recursos complementares ao manual didático. Um professor menciona como central o uso do livro

\footnotetext{
${ }^{1} \mathrm{O}$ professor é identificado pela sua área de conhecimento (B, de Biologia, ou $\mathrm{G}$, de Geografia) e pelo manual que utiliza: Ga, Gb, Gc ou Gd, de Geografia, ou Be e Bf, de Biologia
} 
didático Amabis \& Martho, e a justifica é a de que trabalha com "foco no vestibular". (Professor Be, Entrevista realizada em 10.06.2011)

O professor se apóia no manual didático como recurso para simplificar a transmissão do conhecimento. Ao serem abordados sobre o recurso fundamental que utilizam, foram unânimes nas respostas. Todos utilizam manuais didáticos especializados de geografia e de biologia em aulas de Educação Ambiental.

Alguns professores citam recursos complementares, como artigos de revistas e textos obtidos por meio da internet. Um deles admite que "vez ou outra utiliza vídeos de Ecologia e Biodiversidade". (Professor Be, Entrevista realizada em 10.06.2011)

A unanimidade nessa resposta confirma a hipótese inicial sobre o uso do manual como principal instrumento didático utilizado nas escolas. Entretanto, a análise de cada manual didático indicará a forma como a Educação Ambiental é tratada nas escolas.

Perguntados se existiriam outros recursos didáticos para abordar a EA em sala de aula, as respostas se repetiram: seriam importantes o levantamento de material sobre o Estado de Mato Grosso do Sul; o trabalho de campo, reconhecido como inviável no período noturno; slides preparados pelos estudantes e apresentados com o recurso de data show. Um professor levanta a possibilidade de convite a palestrantes, embora não tenha utilizado o recurso "por encontrar dificuldade com a falta de tempo para tal organização". (Professor Gc, Entrevista realizada em 10.06.2012)

Por fim, foi aberta a possibilidade para que os professores evidenciassem as limitações que, segundo seu entendimento, pesam contra o bom andamento da Educação Ambiental.

As respostas foram: "falta de material sobre Mato Grosso do Sul", (Professor Gb, Entrevista realizada em 10.06.2011) "falta de material didático para pesquisas em laboratório", (Professor Bf, Entrevista realizada em 10.06.2011) "ausência de material para teoria e prática", (Professor Bf, Entrevista realizada em 10.06.2011) "falta de tempo e recurso para o enriquecimento das aulas", (Professor Bf, Entrevista realizada em 10.06.2011), a Secretaria de Estado de Educação não envia vídeos do ensino médio, programação da Vídeo Escola", (Professor Bf, Entrevista realizada em 10.06.2011) "falta de capacitação sobre o código florestal", (Professor Professor Bf, Entrevista realizada em 10.06.2011), "falta de parceria com a universidade", (Professor Bf, Entrevista realizada em 10.06.2011), "o livro didático não traz fatos da mídia - exemplo: a votação do Código Florestal" (Professor Bf, Entrevista realizada em 10.06.2011).

Como se observa, as respostas tergiversam e variam desde os pretextos que atribuem responsabilidades por limitações a entidades externas até os disparates. Mas, os depoimentos demonstram que os professores usam o manual didático como recurso instrumental quase exclusivo em sala de aula, embora afirmem o discutível desejo de explorar outros recursos didáticos. Mais uma vez tergiversam e dizem que a falta de tempo ou de oportunidade os impedem de realizar tal intenção.

Em seguida, é realizada a análise dos manuais didáticos referidos nas entrevistas.

Sete manuais didáticos foram citados pelos professores. Todos foram analisados: quatro de Geografia e três de Biologia. Dois professores de Biologia utilizavam o mesmo título.

Em todos os manuais os temas, meio ambiente e educação ambiental constituem-se unidades ou capítulos específicos. Seguem-se os títulos e breves descrições dos manuais de Geografia (a, b, c $e$ d) e de Biologia (e $e$ f).

a) Título: Geografia Geral e do Brasil: espaço geográfico e globalização

Autor: Eustáquio de Sene e João Carlos Moreira. 
Editora: Scipione, São Paulo

Edição consultada: $1^{\mathrm{a}}$., 1998

O manual apresenta-se em volume único. Entretanto, de acordo com o Guia do Livro Didático (GUIA PNLD, 2011), para o ano de 2012 deverá constituir-se de três volumes. Os conteúdos estão organizados em 7 unidades temáticas e respectivos capítulos. Estes são compostos por texto principal, textos complementares, representações gráficas e cartográficas e atividades.

A unidade 7 tem por tema "Desenvolvimento x meio ambiente" e está dividida em 4 capítulos: 1. Impactos ambientais em ecossistemas naturais e em ecossistemas agrícolas; 2. Impactos ambientais em sistemas urbanos; 3. Outras formas de poluição; 4. Lutas em defesa do meio ambiente. (SENE; MOREIRA, 1998, p. 380-422)

O capítulo 1, já no primeiro parágrafo, diz: "Desde que os mais distantes antepassados do homem atual surgiram na Terra, há mais de 1 milhão de anos, eles vêm transformando a natureza". O texto prossegue citando fatos que apontam o homem como principal agente causador do impacto ambiental. Os autores ressaltam que "a agressão causada pelo homem é contínua, não dando chance nem tempo para a regeneração do meio ambiente". (SENE; MOREIRA, 1998, p. 380)

Nesses dois extratos, o homem é apresentado como transformador e destruidor da natureza. Não há menção ao sistema econômico nem às relações sociais. Cabe somente a ele a responsabilidade pela devastação ambiental. Diante dessa lacuna, não se pode reconhecer no texto uma abordagem crítica, ao contrário do que afirma a análise do Guia do Plano Nacional do Livro Didático - PNLD: "Destacam-se na coleção: a inclusão de uma unidade sobre meio ambiente e processos físicos; a abordagem crítica dos conteúdos econômicos e políticos para o entendimento da produção do espaço geográfico; e os conteúdos de cartografia”. (GUIA PNLD 2011, p. 73, grifo nosso)

Assuntos pertinentes aos capítulos são apresentados nos manuais sem permitir que o leitor reflita sobre eles e elabore ideias com o apoio de autores especializados e pesquisas científicas.

Alguns exemplos demonstram a superficialidade: "Os principais responsáveis pela poluição do ar nas cidades são os transportes, as instalações industriais, as centrais termelétricas, as instalações de aquecimento, etc." (SENE; MOREIRA, 1998, p. 392) Ao discutir os impactos ambientais em ecossistemas agrícolas, os autores referem-se à "fome na África negra, mesmo diante do avanço tecnológico e da revolução agrícola". (SENE; MOREIRA, 1998, p. 387) Não se discute a disponibilidade de alimentos e a capacidade de acesso aos alimentos por parte dos povos em todo o mundo. Não se expõe, claramente, que ao capitalismo pouco interessa atender às necessidades básicas de humanidade. Ele só produz mercadorias que possam se realizar no mercado e viabilizar o lucro.

b) Título: Geografia Geral $\begin{gathered}\text { e do } \\ \text { Autores: TAMDJIAN, James }\end{gathered}$ Onnig;
Editora: FTD, São Paulo.

A parte I desse manual, intitulada "Brasil", divide-se em 11 capítulos: 1. Ocupação do espaço brasileiro; 2. Posição geográfica do Brasil; 3. Paisagens naturais do Brasil: relevo e hidrografia; 4. Paisagens naturais do Brasil: clima e vegetação; 5. Formação da sociedade brasileira; 6. Dinâmica demográfica e qualidade de vida da população brasileira; 7. Industrialização do espaço brasileiro; 8. Urbanização e metropolização do Brasil; 9. 
Atividades agropecuárias no Brasil; 10. Evolução das questões ambientais no Brasil e 11. O papel geopolítico do Brasil.

A parte II, intitulada "Geral", também está dividida em 11 capítulos: 1. A geografia busca compreender o que acontece no espaço e na nossa vida; 2. Cartografia, a ciência dos mapas; 3. Os grandes domínios morfoclimáticos; 4. A evolução da economia mundial; 5. O espaço agrário; 6. O espaço industrial; 7. Fontes de energia; 8. População mundial: quem somos, onde estamos e como vivemos; 9. O mundo urbanizado; 10. Os grandes conflitos internacionais e 11. Quadro ambiental do planeta.

Toma-se para análise o capítulo 10 da parte I e o capítulo 11 da parte II, por tratarem mais especificamente da questão ambiental.

O capítulo 10 traz uma síntese do que o aluno vai aprender.

"Os mais importantes problemas ambientais brasileiros e os graves prejuízos que acarretam para o espaço e a sociedade. O conceito de desenvolvimento sustentável e as possibilidades de aplicar tal conceito para assegurar existência duradoura da rica paisagem natural". (TAMDJIAN; MENDES, 2004, p.6)

O capítulo estrutura-se de forma a envolver texto principal, textos complementares, representações gráficas e cartográficas, atividades e questões de vestibular.

O texto principal afirma que a intensa destruição do meio ambiente, ao longo da história, está "vinculada intimamente ao modelo de desenvolvimento econômico adotado desde o início da colonização". O caso do Brasil não seria diferente: "Aqui, da mesma forma que nos países mais desenvolvidos, a busca do lucro foi sempre prioritária, em detrimento da natureza." (TAMDJIAN; MENDES, 2004, p. 562)

O caminho para a implantação da agricultura foi aberto com o desmatamento descontrolado, desde a exploração da cana-de-açúcar na Zona da Mata nordestina, durante o século XVI, o cultivo do café em São Paulo, no século XIX, até o cultivo de soja no centro-oeste, mais recentemente, que alterou o ecossistema do cerrado em pouco mais de três décadas.

Também neste manual a sociedade não é tratada concretamente. Expressões como "modelo de desenvolvimento econômico" e "países mais desenvolvidos", são recursos para velar ou tangenciar o caráter predatório que marca a atuação do capital. Dessa forma, ele deixa de ser responsabilizado diretamente pela destruição dos recursos naturais e pelos prejuízos ao equilíbrio ambiental que ameaçam a vida no planeta.

c) Título: Panorama Geográfico do Brasil: contradições, impasses e desafios

Autores: M. Adas e S. Adas.

Editora: Moderna, São Paulo.

Edição consultada: $3^{\mathrm{a}}$., 2002.

O conjunto de capítulos, somado ao todo 29, distribui-se em quatro unidades. Os conteúdos de cada capítulo compõe-se de uma epígrafe, texto principal, textos complementares, representações gráficas e cartográficas, exercícios e aprofundamento.

Foi analisado apenas o capítulo cujo tema relaciona-se diretamente ao objeto de estudo. A especificidade do capítulo 11, integrante da Unidade 2, página 160, chama a atenção: "Que modelo de desenvolvimento é esse que deteriora o meio ambiente e beneficia a minoria?"

A obra traz conceitos principais e complementares. Os principais são a sociedade de consumo, recursos naturais, desperdício, abundância e escassez, desequilíbrios ecológicos, justiça social, desarmonia entre os homens, dentre outros. Os conceitos 
complementares tratam de ética, movimentos ambientalistas; ONGs - Organizações NãoGovernamentais, exploração racional dos recursos naturais, silvicultura extensiva etc.

O manual didático oferece ao professor roteiro de trabalho a ser desenvolvido com os alunos. Em relação às atividades, apresenta sugestão cujo objetivo, segundo o autor, é "aprimorá-las, por meio de indicação de leituras, que servem para aprofundamento dos temas, bem como lapidar os assuntos que foram objetos de estudo dos capítulos". Ainda segundo os autores,

(...) há filmografias de produções brasileiras e outras, dispostas nas locadoras, para tornar o estudo dos assuntos mais estimulantes. Obras de ficção e outros gêneros com o propósito de estimular a leitura para o aperfeiçoamento de sua linguagem e raciocínio. (ADAS; ADAS, 2002, p. 6)

O breve texto apresentado pelo manual é de fácil leitura, não leva o leitor à reflexão, e, para garantir o "aprofundamento", são recomendadas ao estudante, ao final do capítulo, algumas leituras complementares, uma filmografia e uma obra de ficção.

A referência básica não é a sociedade capitalista, mas uma abstrata sociedade de consumo, que, segundo os autores, pode ser expressa por valores sociais cujas determinações não são esclarecidas.

Ostentar roupas das melhores griffes e carros sofisticados e caros, morar em mansões ou apartamentos suntuosos, viajar ao exterior e comprar as últimas novidades do mercado tornaram-se os parâmetros para medir o sucesso individual na sociedade. (ADAS; ADAS, 2002, p.160)

d) Título: Geografia - Geografia Geral e do Brasil (3 volumes)

Autora: Lúcia Marina Alves de Almeida

Editora: Ática, São Paulo

Edição consultada: 2005

A coleção é composta por três volumes, organizados em unidades, subdivididas em capítulos e seções. O volume 1 contém 328 páginas, divide-se em 7 unidades, com total de 25 capítulos. O volume 2 contém 312 páginas e divide-se em 5 unidades, com 27 capítulos. O volume 3 contém 328 páginas e divide-se em 6 unidades, com 25 capítulos. Em todos os capítulos, além do texto principal e dos complementares, encontram-se diversas ilustrações, mapas, gráficos e fotografias, seguido s de sugestões de atividades e o final "Questões para reflexão e Glossário". Ao longo dos capítulos, intercalam-se as seções Leitura e reflexão, Contexto e aplicação, Relacionando os assuntos, Outra visão, O que há de novo e Pesquise e reflita. Todas as unidades terminam com as seções "Concluindo a unidade", que contém textos complementares, questões de vestibulares e do Enem, e "Outras fontes de reflexão e pesquisa", com a indicação de filmes, livros e sites. Ao final de cada volume, apresentam-se as seções Significado das siglas, Referências Bibliográficas e Índice remissivo. (ALMEIDA, 2005, p. 134-41)

O espaço disponível para os textos é pequeno e, portanto, o conteúdo não aprofunda o assunto. Reconhecendo implicitamente o fato, o manual traz sugestões de leituras "complementares" e filmes/documentários ao final de cada capítulo.

A questão ambiental no Brasil é parte da unidade 6 do manual didático em referência.

Ao tratá-la, no texto principal, a autora refere-se ao homem como o responsável pela quebra do equilíbrio ecológico. 
A harmonia nas relações entre os seres vivos e o meio ambiente é chamada de equilíbrio ecológico. Ao quebrar essa harmonia, o homem provoca o que chamamos de impacto ambiental. As causas dessa quebra vêm se intensificando durante a história do homem; fatores como o aumento populacional e o desenvolvimento tecnológico, no decorrer do tempo, intensificaram rapidamente a dimensão desses impactos. (ALMEIDA, 2005, p. 287)

Mas, em contrapartida, o homem também é punido por seus desatinos.

Toda essa agressão à natureza não ficou impune. Os inúmeros impactos ambientais ocorridos na história da humanidade trouxeram para a sua espécie, o homem, problemas que ameaçam não só sua sobrevivência na Terra, como a dos demais seres vivos. (ALMEIDA, 2005, p. 289)

O capítulo passa superficialmente sobre conceitos como "história". A sociedade capitalista, a forma histórica de sociedade em nosso tempo, nem é referida. "Os impactos ambientais eram muito pequenos no início da história do homem. O aumento populacional e o desenvolvimento tecnológico, no decorrer do tempo, intensificaram rapidamente a dimensão desses impactos". (ALMEIDA, 2005, p.134)

É necessário enfatizar sempre, quanto a esse aspecto, que não se trata do homem entendido abstratamente, tal como aparece no texto, e sim da relação histórica denominada capital, que afasta o homem da natureza e a usa desmedidamente.

Os diversos volumes também oferecem sugestão metodológica ao professor, conforme preconizam os apêndices do edital PNLD para o Ensino Médio (2009) sob o título de "Recursos didático-pedagógicos". Contêm

Orientações para o docente exercer suas funções em sala de aula, bem como uma bibliografia diversificada e sugestões de leitura, propostas de atividades individuais e em grupo, e sugestões de diferentes formas de avaliação. (BRASIL, 2009, p. 29)

e) Título: Bio (3 volumes)

Autores: Sergio Rosso e Sônia Lopes

Editora: Saraiva, São Paulo

Edição consultada: 2010

$\mathrm{O}$ volume 1 contém duas unidades. A primeira trata dos seguintes conteúdos: "O mundo em que vivemos: Introdução à Biologia"; "Introdução à Ecologia"; "Ecossistemas terrestres e aquáticos"; "Estrutura dos ecossistemas, fluxo de energia e ciclo da matéria"; "Comunidades e populações" e "A quebra do equilíbrio ambiental". A Unidade 2 envolve "Origem da vida e Biologia celular: das origens aos dias de hoje"; "A química da vida"; "Citologia e envoltórios celulares"; "O citoplasma"; "Metabolismo energético" e "Núcleo, divisões celulares e reprodução".

O volume 2 contém três unidades. A primeira inclui os seguintes conteúdos: "A espécie humana: Reprodução humana"; "Embriologia humana"; "Estrutura e função dos epitélios e dos tecidos conjuntivos"; "Estrutura e função dos tecidos musculares e do tecido nervoso"; "Sistemas digestório, respiratório, cardiovascular e imunitário" e "Sistema urinário, nervoso e endócrino". A Unidade 2 contém as matérias "Genética: a genética e os genes"; "A herança de uma característica"; "A Herança simultânea de duas ou mais características"; "Outros mecanismos da herança" e "Biotecnologia". A Unidade 3 envolve "Evolução: Processos evolutivos" e "Genética de populações e especiação". 
O volume 3 contém três unidades. A primeira inclui "Classificação dos seres vivos e estudo dos vírus, procariontes e protistas: evolução e classificação"; "Vírus"; "Procariontes" e "Protistas". A Unidade 2 envolve "Plantas: evolução e classificação das plantas"; "Histologia e morfologia das angiospermas" e "Fisiologia das angiospermas". A Unidade 3 contém as matérias "Os Fungos e os animais: fungos"; "Origem, evolução e características gerais dos animais"; "Forma e função dos animais: um estudo comparado"; "Diversidade animal I"; "Diversidade animal II"; "Diversidade animal III", "Diversidade animal IV" e "Evolução humana".

Apenas no capítulo 6 do volume 1, intitulado "A quebra do equilíbrio ambiental", são abordados problemas ambientais como a poluição, as causas do aquecimento global, além do desenvolvimento sustentável.

O capítulo norteia-se pela ideia de

que o ser humano é em parte responsável pelo aquecimento global com suas emissões de gases estufa, mas ele também pode ser o responsável por evitar que o aquecimento global aumente, utilizando-se de tecnologias já existentes e aperfeiçoando-as. (ROSSO; LOPES, Manual do professor, 2010, p. 49)

Em seguida, são apresentadas imagens com diferentes datas, para demonstrar, por meio de comparação, as áreas desmatadas para o plantio de soja na região Centro-oeste. Uma imagem mostra a vegetação nativa sendo queimada para dar lugar a áreas de pecuária e agricultura. A figura aponta os locais de maior interferência humana (antrópica) em ecossistemas naturais, passíveis de desequilíbrios que podem colocar em risco toda a trama de relações que levou centenas ou milhares de anos para se estabelecer.

A abordagem define os tipos de poluição ambiental, discute a ação humana nas comunidades naturais e vê a aplicação do conhecimento ecológico como um caminho para minimizar os impactos causados no ambiente.

Como é dominante nos manuais didáticos, as relações sociais não se revelam. A dinâmica da sociedade capitalista e as leis que lhe dão movimento permanecem veladas. $\mathrm{O}$ homem abstrato é a entidade que ameaça o ambiente e não o capital, entendido como relação social.

f) Título: Biologia (Volume 1 - Biologia das células/ Volume 2 - Biologia dos organismos/ Volume 3- Biologia das populações)

Autores: José Mariano Amabis e Gilberto Rodrigues Martho

Editora: Saraiva, São Paulo

Edição consultada: 2010

A obra é estruturada em três volumes. Cada volume está organizado em capítulos que se relacionam a um tema mais amplo da Biologia. Os capítulos são compostos por seções que abordam itens específicos.

A abertura dos capítulos é feita por imagens e pequenos textos que ilustram os assuntos e a ideia central do tema tratado. Na página inicial, encontra-se em destaque a seção denominada "Para pensar", que propõe questionamento e uma problematização sobre o assunto.

No início de cada seção estão indicadas as habilidades e os conceitos mais relevantes referentes à temática abordada. Ao final, encontram-se duas atividades de avaliação: "Questões para pensar e discutir", com sugestões de atividades e de pesquisas para discussão e aprofundamento dos assuntos, e "Vestibulares pelo Brasil", com questões de vestibulares realizados no país. (AMABIS; MARTHO, 2010, s. n.) 
Grande parte dos capítulos contém um quadro denominado "Ciência e Cidadania". Nele são apresentados textos para subsidiar o estudo de temas em destaque, relacionando ciência, cotidiano e exercício da cidadania. Acompanha-o um "Guia de Leitura" para orientar o estudo. (AMABIS; MARTHO, 2010, s.n.)

O Volume III tem 376 páginas. Nele a Genética é trazida em seus conceitos clássicos ao lado de novos conhecimentos nas áreas de Biologia Molecular e Engenharia Genética. Em seguida, são tratados os princípios da Evolução Biológica, tema que leva à reflexão sobre a origem e o desenvolvimento da vida e da espécie humana. Por fim, a obra apresenta os conceitos básicos de Ecologia. Nessa parte os autores comentam os desafios enfrentados pela humanidade para preservar o ambiente terrestre.

Ressalte-se que apenas a unidade $\mathrm{C}$ do volume III trata de questões relacionadas ao meio ambiente. No quadro "Ciência e cidadania", há um texto sobre as populações humanas, intitulado "Quando o crescimento da população humana vai parar?", que traz a ilustração gráfica do crescimento populacional entre 8.000 a.C. e 2.050 d.C. Os dados são baseados na Encyclopaedia Britannica. (AMABIS; MARTHO, 2010, p. 357)

Sobre esse manual didático, chama atenção a análise exposta no guia de livros didáticos do Programa Nacional do Livro Didático para o Ensino Médio. Em certo momento, adverte os professores sobre "algumas explicações que trazem solução apenas parcial para problemas relacionados à saúde humana, desconsiderando impactos sobre outros organismos". É o caso das medidas contra a esquistossomose, que preconizam o "uso de substâncias para matar moluscos em águas de lagoas e a introdução de tilápias, como meio para controle de cercárias, sem que seja feita uma discussão sobre o impacto ambiental causado por elas". (GUIA DE LIVROS DIDÁTICOS, 2009, p. 66)

Após esta análise do conteúdo dos manuais didáticos utilizados em Geografia e Biologia nas escolas de Ensino Médio, saliente-se, ainda, que a importância do tema meio ambiente não pode ser apreendida por meio desse instrumento de trabalho especializado. Ele inviabiliza a abordagem interdisciplinar e reforça essa limitação por induzir uma metodologia que não rompe com a visão especializada do professor.

Isso é preocupante, pois a educação ambiental nas escolas passa a acomodar-se à subdivisão das disciplinas curriculares. Pelas abordagens especializadas ela se isola no interior de diferentes áreas do conhecimento, modo insuficiente para a compreensão dos fenômenos ambientais em sua totalidade. Enfim, a falta de articulação interdisciplinar imposta pelos manuais didáticos impede que haja o debate que está na base da proposta do tema transversal.

\section{Conclusão}

A Educação Ambiental surgiu como resposta aos problemas ambientais desencadeados no interior da sociedade capitalista.

No Brasil, a Constituição Federal de 1988 elevou ao primeiro plano o direito à educação ambiental ao mencioná-la como um componente essencial para preservar a qualidade de vida na terra.

Daí a relevância e a inserção do meio ambiente nas diretrizes curriculares como tema transversal.

Ao verificar como a Educação Ambiental é tratada na escola de ensino médio em Campo Grande, MS, constatou-se, a exemplo do que já afirmara Alves (2005, 2008 e 2004), que o manual didático, instaurado no século XVII, ainda é o principal instrumento de transmissão de conhecimento. Como os manuais das diferentes áreas do currículo são especializados, o meio ambiente, ao contrário do que postulam a legislação e as diretrizes 
curriculares que norteiam a educação, deixa de ser, objetivamente, um tema transversal. Este estudo demonstrou esse fato ao analisar como os professores utilizam os manuais didáticos especializados de Biologia e Geografia.

A transversalidade implicaria a relação entre todos os professores, exigindo, inclusive, um planejamento em comum ou interdisciplinar em torno do tema. Caberia a cada área de conhecimento discutir a sua forma de contribuição específica para a Educação Ambiental. O uso privilegiado desses instrumentos para a formação dos estudantes é um caminho que compromete a proposta de transversalidade preconizada nas leis, nas políticas, bem como nos referenciais curriculares.

Os professores de Biologia e Geografia, cujas áreas do conhecimento estão mais diretamente ligadas à Educação Ambiental, estão sendo induzidos a tratar da questão ambiental direta e isoladamente, pois os manuais didáticos especializados das respectivas disciplinas passaram a incorporar unidades denominadas Educação Ambiental. Essa iniciativa só reforça a abordagem disciplinar.

\section{Referências}

ADAS, M.; ADAS, S. Panorama geográfico do Brasil: contradições, impasses e desafios socioespaciais. São Paulo, SP: Moderna, 2002.

AMABIS, J. M; MARTHO, G. R. Biologia das populações: genética, evolução biológica e ecologia. Vol.3. São Paulo, SP: Moderna, 2010.

ALMEIDA, L. M. A. de. Geografia: geografia geral e do Brasil. São Paulo: Ática, 2005.

ALVES, G. L. O trabalho didático na escola moderna: formas históricas. Campinas, SP: Autores Associados, 2005.

A produção da escola pública contemporânea. 2. ed. Campinas, SP: Autores Associados, 2004.

Formação de professores: uma necessidade de nosso tempo? Revista Histedbr, Campinas, n.31, p.102-112, ISSN: 1676 - 2584, set. 2008. Disponível em: $<$ http://www.histedbr.fae.unicamp.br/revista/edicoes/31/art08_31.pdf >. Acesso em: 5 jan. 2012.

BRANCO, S. M. O meio ambiente em debate. 26. ed. São Paulo: Moderna, 1997.

BRASIL. Lei n. 9.795 de 27 de abril de 1999. Dispõe sobre a educação ambiental, institui a Política Nacional de Educação Ambiental. Disponível em:

<www.mma.gov.br/conama/legiabre>. Acesso em: 11 dez. 2010.

Constituição Federal (1988). Constituição da República Federativa do Brasil: promulgada em 5 de outubro de 1988. Contém as emendas constitucionais. Brasília, DF: Senado, 2008. Disponível em: 〈http://www.planalto.gov.br>. Acesso em: 1 mar. 2011.

Ministério de Educação; Conselho Nacional de Educação; Câmara de Educação Básica. Resolução $N^{\circ} 2$. Promulgada em 30 de jan. de 2012. Define diretrizes curriculares para o ensino médio. 2012.

Secretaria de Educação Fundamental. Parâmetros curriculares nacionais: apresentação dos temas transversais, ética. Secretaria de Educação Fundamental. Brasília: MEC/SEF, 1997. 
Ministério da Educação. Fundo Nacional de Desenvolvimento da Educação. Programa nacional do livro didático. Brasília: MEC, FNDE, 2009. Disponível em: <http://www.fnde.gov.br/index.php/programas-livro-didatico>. Acesso em: 12 jan. 2011.

BURSZTYN, M.; PERSEGONA, M. A grande transformação ambiental: uma cronologia da dialética do homem-natureza. Rio de Janeiro: Garamond, 2008.

BUSQUETS, M. D. et alii. Temas transversais em educação: bases para uma formação integral. São Paulo: Ática, 1997.

COMENIUS, Iohannis. A. Didática magna (1621-1657). Fundação Calouste Gulbenkian, 2001. Versão para ebooks. Disponível em: www.EbooksBrasil.org>. Acesso em: $10 \mathrm{dez}$. 2011.

ENGELS, F. Dialéctica da natureza. 2. ed. São Paulo: Martins Fontes, 1978. . A situação da classe trabalhadora na Inglaterra. São Paulo, SP: Global, 1985.

FALEIROS, Fábio. Revolução verde. Revista Vida Simples. EMBRAPA, agosto de 2007. In: Planeta Sustentável. Disponível em:

<http://planetasustentavel.abril.com.br/noticia/atitude/conteudo_244070.shtml >. Acesso em: 3 fev. 2011.

GUIA DE LIVROS DIDÁTICOS: PNLD: Geografia. Brasília: Ministério da Educação, Secretaria da Educação Básica, 2011, 120p. Disponível em: http://portal.mec.gov.br. Acesso em: 12 de mar. 2012.

GUIA DE LIVROS DIDÁTICOS: PNLEM: Biologia. Brasília: Ministério da Educação, Secretaria da Educação Básica, 2009. Disponível em: http://www.fnde.gov.br. Acesso em: 12 mar.2012.

GUIMARÃES, M. A dimensão ambiental na educação. 8. ed. Campinas, SP: Papirus, 2007.

HERMAN, A. A ideia de decadência na história ocidental. 2. ed. Rio de Janeiro: Record, 2001.

HOBSBAWM, E. A era do capital: 1848 - 1875. São Paulo, SP: Paz e Terra, 2004.

INSTITUTO BRASILEIRO DE GEOGRAFIA E ESTATÍSTICA - IBGE. Censo Demográfico. Tendências demográficas: Uma Análise da População com Base nos Resultados dos Censos Demográficos de 1940 e 2000. Comunicação Social, 25 maio 2007. Disponível em: < http://www.ibge.gov.br/home/presidencia/noticias>. Acesso em: 7 jan. 2011.

INSTITUTO BRASILEIRO DO MEIO AMBIENTE E DOS RECURSOS NATURAIS RENOVÁVEIS - IBAMA ; UMA- Universidade Livre da Mata Atlântica. Perspectivas do meio ambiente mundial: GEO - vol. 3, 2004.

LEMOS, E. M. A fundação para conservação da natureza de Mato Grosso do Sul FUCONAMS e as origens do movimento ambientalista no estado: 1979 a 1989.

Dissertação de mestrado. Biblioteca digital Anhanguera/Uniderp, Campo Grande, MS, 2004. Disponível em: <www.anhanguerauniderp.com.br.>. Acesso em: 21 out. 2010.

MÉSZÁROS, I. O século XXI: socialismo ou barbárie? São Paulo: Boitempo Editorial, 2003. 
MÉSZÁROS, I. Crise estrutural necessita de mudança estrutural. Texto base da Conferência proferida no II Encontro de São Lázaro. Faculdade de Filosofia e Ciências Humanas da UFBA. 13 de jun. 2011. Disponível em:

ffch.ufba.br/IMG/pdf/Conferencia_Meszaros.pdf. Acesso em: 12 jun. 2012.

MILARÉ, E. Legislação ambiental do Brasil. São Paulo: APMP, 1991.

PROGRAMA DAS NAÇÕES UNIDAS PARA O DESENVOLVIMENTO- PNUD.

Desenvolvimento humano sustentável. Brasília, DF: Relatório sintético das atividades do PNUD no Brasil: 1960 - 2002, 1992. Disponível em: <http://www.pnud.org.br/pnud/>. Acesso em: 5 ago. 2010.

RIBEIRO, D. O processo civilizatório: etapas da evolução sociocultural. São Paulo: Companhia das Letras, 1998.

ROSSO, Sergio; LOPES, Sônia. Bio. Vol. 1, 2 e 3. São Paulo, SP: Saraiva, 2010.

SENE, E.; MOREIRA, J. C. Geografia geral e do Brasil: espaço geográfico e globalização. São Paulo, SP: Scipione, 1998.

TAMDJIAM, J. O; MENDES, I. L. Geografia geral e do Brasil. Vol. único. São Paulo, SP: FTD, 2004.

VIOLA, E. ; LEIS, H. R. Desordem global da biosfera e a nova ordem internacional: o papel organizador do ecologismo. Petrópolis, RJ: Vozes, 1992.

Recebido em dezembro-12

Aprovado em março-13

Notas

\footnotetext{
${ }^{1}$ Graduada em Letras. Especialista em Metodologia do Ensino de Língua Portuguesa. Mestra em Meio Ambiente e Desenvolvimento Regional pela Universidade Anhanguera - Uniderp, MS.

${ }^{2}$ Professor aposentado da UFMS, atualmente professor do Curso de Mestrado em Meio Ambiente e Desenvolvimento Regional na Universidade Anhanguera - Uniderp, MS.

${ }^{3}$ IDH- Índice de Desenvolvimento Humano: para medir a longevidade, utiliza-se a esperança de vida ao nascer, em anos. Para mensurar o acesso ao conhecimento, emprega-se a taxa de matrícula nos três níveis de ensino (peso 1/3) e taxa de alfabetização de pessoas com 15 anos ou mais (peso 2/3). Após a apuração de dados estatísticos de cada dimensão, é feita uma média aritmética dos três índices (IDH- Renda, IDHLongevidade e IDH- Educação), cujo resultado varia entre o mínimo de zero e o máximo de um.
} 